\title{
Thermal stability of ultra-wide-bandgap MgZnO alloys with wurtzite structure
}

\author{
Dinesh Thapa ${ }^{1}$ - Jesse Huso ${ }^{1}$. Jeffrey Lapp ${ }^{1}$ - Negar Rajabi ${ }^{1}$. John L. Morrison ${ }^{2}$ - Matthew D. McCluskey ${ }^{3}$. \\ Leah Bergman ${ }^{1}[$ ]
}

Received: 13 May 2018 / Accepted: 27 July 2018 / Published online: 7 August 2018

(c) The Author(s) 2018

\begin{abstract}
$\mathrm{Mg}_{\mathrm{x}} \mathrm{Zn}_{1-\mathrm{x}} \mathrm{O}$ thin films were grown as metastable alloys via a sputtering technique in order to achieve single-phase wurtzite alloys with deep-UV optical bandgaps. As-grown alloys with $\mathrm{Mg}$ composition range $0-72 \%$ resulted in optical bandgaps spanning the UV-range of 3.3-4.4 eV. The thermal stability of the alloys was studied via post-growth controlled annealing experiments up to $900{ }^{\circ} \mathrm{C}$. Alloys with low $\mathrm{Mg}$ up to $34 \%$ were found to be highly stable and retained their optical and material properties; however, alloys with higher $\mathrm{Mg}$, up to $72 \%$, were found to be unstable and were phase separated into wurtzite and cubic structural phases with respective optical bandgaps at $\sim 3.5$ and $6.0 \mathrm{eV}$. Both the as-grown and annealed alloys were studied using X-ray diffraction for structural identification, transmission spectroscopy for bandgap analysis, and Raman scattering for mapping the phonon mode-behavior. The experimental value for the solubility limit was found to be $\sim 30 \%$. A straightforward model calculation based on the Raman-mode saturation behavior yielded a similar value for the solubility limit of the alloys. The results are discussed in terms of available phase-diagrams for stable-state ceramics alloys that were grown under thermodynamics equilibrium conditions.
\end{abstract}

\section{Introduction}

Ternary semiconductor alloys are important materials in device technologies, enabling bandgaps by design with tailored values for a specific application [1-3]. The bandgaps can span large energy ranges depending on the two end-members of the alloy. However, due to different crystal structures of the end-members or size difference of the substituting atoms, some alloy systems may exhibit a particular range in composition for which the alloy is not soluble, and mixed phases co-exist. To overcome this issue of solubility limit the films can be grown far from their thermodynamics equilibrium conditions as metastable alloys $[1,2,4,5]$. Usually low growth temperatures inhibit the kinematics of the diffusion and re-nucleation of a second phase, and the

Leah Bergman

Lbergman@uidaho.edu

1 Department of Physics, University of Idaho, Moscow, ID 83844-0903, USA

2 Division of Natural Sciences and Mathematics, Lewis-Clark State College, Lewiston, ID 83501, USA

3 Department of Physics and Astronomy, Washington State University, Pullman, WA 99164-2814, USA resulting film may be a single phase alloy. A key point is the thermal stability of such films for applications at elevated temperatures. This research focuses on the thermal stability of $\mathrm{Mg}_{\mathrm{x}} \mathrm{Zn}_{1-\mathrm{x}} \mathrm{O}$ thin films, at a large composition range $0 \leq \mathrm{x} \leq 0.72$, that were synthesized far from their thermodynamics equilibrium conditions as wurtzite single phase alloys. To our knowledge, to date there are few comprehensive studies on that topic [6-8]; results from related work will be discussed in detail in the paper. This research may contribute to the fields of thermal management of potential $\mathrm{MgZnO}$-based high-power devices and electronics operating at harsh environments.

$\mathrm{Mg}_{\mathrm{x}} \mathrm{Zn}_{1-\mathrm{x}} \mathrm{O}$, where $\mathrm{x}$ is the composition, is an alloy system with optical properties that in principle can span a large range of the UV spectrum starting at $\sim 3.3 \mathrm{eV}(375 \mathrm{~nm})$, which is the bandgap of $\mathrm{ZnO}$, and ending at $\sim 7.7 \mathrm{eV}$ $(161 \mathrm{~nm})$ which is that of $\mathrm{MgO}[1,9] . \mathrm{Zn}$ and $\mathrm{Mg}$ have comparable atomic and ionic sizes that may promote good solubility, however each end member has a different crystal structure: hexagonal-wurtzite for $\mathrm{ZnO}$ and cubic-rocksalt for $\mathrm{MgO}$, which render them insoluble at some intermediate composition range. At that range the alloy is phase separated into $\mathrm{Zn}$-rich domains with the wurtzite structure and $\mathrm{Mg}$ rich domains with the cubic structure. The phase equilibrium 
diagram for the $\mathrm{MgO}-\mathrm{ZnO}$ solid-solution ceramics grown at elevated temperatures tentatively suggested that that the solubility of $\mathrm{Mg}$ into the $\mathrm{ZnO}$ wurtzite matrix is extremely limited on the order of $x \sim 0.04$ [10]. On the other hand more recent work on such ceramics alloy system showed a more substantial $\mathrm{Mg}$ solubility of $\mathrm{x} \sim 0.15$ [11].

In contrast to the ceramics, $\mathrm{Mg}_{\mathrm{x}} \mathrm{Zn}_{1-\mathrm{x}} \mathrm{O}$ thin films were found to exhibit a significant solubility that depends on the deposition method. Previous study on $\mathrm{Mg}_{\mathrm{x}} \mathrm{Zn}_{1-\mathrm{x}} \mathrm{O}$ thin films, deposited via pulsed laser deposition (PLD), has found that this alloys were single-phase with the wurtzite structure up to a $\mathrm{Mg}$ composition $\mathrm{x} \sim 0.33$; above that the alloys were found to be phase separated [1]. Single-phase wurtzite with high $\mathrm{Mg}$ composition $\mathrm{x}=0.5$ were also grown via molecular beam epitaxy [12], while more recent work used pulsed metal organic chemical vapor deposition to achieve single phase wurtzite alloys up to $x=0.51$ [13]. The crystallization of single phase wurtzite alloys with large $\mathrm{Mg}$ composition, as opposed to that of the ceramics, was attributed to the nonequilibrium nature of the deposition methods thus enabling the growth of metastable alloys.

The realization of high $\mathrm{Mg}$ composition films with a wurtzite structure may increase the functionality of this system by enabling tunable bandgaps over a substantial range of the UV spectrum. Advances in the material issues of $\mathrm{Mg}_{\mathrm{x}} \mathrm{Zn}_{1-\mathrm{x}} \mathrm{O}$ thin films may lead to applications including $\mathrm{MgZnO} p-n$ heterostructure light-emitting devices that operate at $355 \mathrm{~nm}$ [14], plasmonic generation in Ga-doped $\mathrm{MgZnO}$ for solar cell technologies [15], and solar-blind UV detectors with a cutoff at $270 \mathrm{~nm}$ [16]. Additionally, it has been found that the $\mathrm{MgZnO}$ thin film transistors at the small $\mathrm{Mg}$ composition range $\mathrm{Mg}_{0.06} \mathrm{Zn}_{0.94} \mathrm{O}$ have better device performance than pure $\mathrm{ZnO}$ channel devices [17]. The reason given was that the incorporation of $\mathrm{Mg}$, due to its strong $\mathrm{Mg}-\mathrm{O}$ bonding, suppresses the oxygen vacancy type defects [17].

Significant efforts have focused on the growth issues of the $\mathrm{Mg}_{\mathrm{x}} \mathrm{Zn}_{1-\mathrm{x}} \mathrm{O}$ films and their nanostructures, however less attention has been given to their thermal stability, which can be a key issue for metastable grown alloys. At the activation temperature, the alloy may transform into its equilibrium crystalline state which can result in multiple structural domains in a film. In this research we focus on the thermal stability study of single-phase $\mathrm{Mg}_{\mathrm{x}} \mathrm{Zn}_{1-\mathrm{x}} \mathrm{O}$ thin films with the wurtzite structure. $\mathrm{Mg}_{\mathrm{x}} \mathrm{Zn}_{1-\mathrm{x}} \mathrm{O}$ alloys up to $\mathrm{x}=0.72$ were grown via a sputtering technique at a relatively low temperature of $250^{\circ} \mathrm{C}$. The as-grown alloys were found via $\mathrm{X}$-ray diffraction (XRD) and transmission studies to possess a single-phase wurtzite structure with a bandgap range $\sim 3.3-4.42 \mathrm{eV}$. The extent of their thermal stability was studied via controlled post-growth annealing in $\mathrm{Ar}$ atmosphere up to $900{ }^{\circ} \mathrm{C}$. The study shows that alloys with low $\mathrm{Mg}$ up to $\mathrm{x}=0.34$ were found to be highly stable and retain their optical and material properties. Alloys with higher $\mathrm{Mg}$, up to $\mathrm{x}=0.72$, were found to be unstable and were phase-separated into cubic phases with bandgaps $\sim 6 \mathrm{eV}$, and wurtzite phases with bandgaps $\sim 3.5 \mathrm{eV}$. The thermal study also indicates that the solubility limit of our alloys is $\mathrm{x} \sim 0.25 \pm 0.05$, and it is discussed in terms of previous available phase-diagrams.

The motivation for the research presented in this paper is as follows. A key focus of ongoing scientific research is the growth of metastable $\mathrm{Mg}_{\mathrm{x}} \mathrm{Zn}_{1-\mathrm{x}} \mathrm{O}$ alloys so as to achieve a single-phase alloy system which is useful for many technological applications. A technique that is typically widely used to improve the optical and material quality of the alloys is annealing. However, due to the solubility limit of the $\mathrm{Mg}_{\mathrm{x}} \mathrm{Zn}_{1-\mathrm{x}} \mathrm{O}$ alloy system, upon supplying the thermal energy via the annealing process, the metastable alloys can become phase separated and no longer retain their desirable singlephase character. The solubility limit issue for $\mathrm{Mg}_{\mathrm{x}} \mathrm{Zn}_{1-\mathrm{x}} \mathrm{O}$ to date is still an open question, which may be due to the various growth techniques that are being employed for achieving this alloy system, and due to the microstructure nature of the alloys. In this paper we analyzed wurtzite metastable $\mathrm{Mg}_{\mathrm{x}} \mathrm{Zn}_{1-\mathrm{x}} \mathrm{O}$ thin film alloys that were grown via the sputtering technique to comprehend their stability properties across the entire composition range.

The novelty of our research is a comprehensive experimental study that includes XRD, transmission, and Raman scattering which was conducted for samples that span almost the entire composition range in order to pinpoint their thermal stability and to acquire a reliable measure to the solubility limit. This was done in conjunction with a straightforward model calculation based on the Raman-mode saturation behavior which enables the analytical determination of the solubility limit of the alloys.

\section{Experiment}

In this study, $\mathrm{Mg}_{\mathrm{x}} \mathrm{Zn}_{1-\mathrm{x}} \mathrm{O}$ with composition $\mathrm{x}=0,0.17,0.34$, $0.52,0.72$ and 0.80 were grown utilizing a DC/RF reactive magnetron sputtering. The chamber was evacuated to a base pressure of $10^{-6}$ Torr before deposition of the films. Sputtering was performed at a total working pressure of 11 mTorr, achieved by passing high purity $\mathrm{Ar}$ and $\mathrm{O}_{2}$ inside the chamber as working and reactive gases respectively. Flow of the gas inside the chamber was regulated using MKS $\mathrm{p} 4 \mathrm{~b}$ digital mass flow controllers. During sputtering, custom $\mathrm{Mg}-\mathrm{Zn}$ metallic targets were used, and the delivered power was $30 \mathrm{~W}$. Films were grown for $\sim 2 \mathrm{~h}$ on (0001) sapphire and (111) $\mathrm{CaF}_{2}$ substrates. The growth temperatures were $250{ }^{\circ} \mathrm{C}$. The thickness of the films were estimated to be $\sim 400 \mathrm{~nm}$ as determined via thin film interference [18].

The as-grown films were subjected to post annealing treatments at 750 and $900{ }^{\circ} \mathrm{C}$ for $1 \mathrm{~h}$ under controlled $\mathrm{Ar}$ 
environment in a Lindberg furnace. Structural phase of the alloy films was investigated by XRD using a Siemens Diffractometer D5000 with the CuK $\alpha 1$ line in $2 \theta$ mode with scan step size of $0.02^{\circ}$. At all steps of the annealing experiments, the alloy compositions of the films were determined via energy dispersive X-ray spectroscopy (EDS). Only minor changes were observed relative to the as-grown films. For the transmission experiments, an Agilent 300 Cary UV-vis transmission system was used in double beam mode.

\section{Results and discussion}

We first address the study of alloys with relatively low-Mg compositions. Figures 1 and $2 \mathrm{a}, \mathrm{b}$ present the XRD and the transmission spectra, respectively, of the $\mathrm{Mg}_{0.17} \mathrm{Zn}_{0.83} \mathrm{O}$ and $\mathrm{Mg}_{0.34} \mathrm{Zn}_{0.66} \mathrm{O}$ samples. The bandgaps were estimated via the transmission derivative method, $\mathrm{dT} / \mathrm{dE}$, that was shown to be a useful approach for ascertaining bandgaps of alloys [19], and in particular provides a suitable definition of bandgap for the alloys studied in this paper. Usually, the transmission

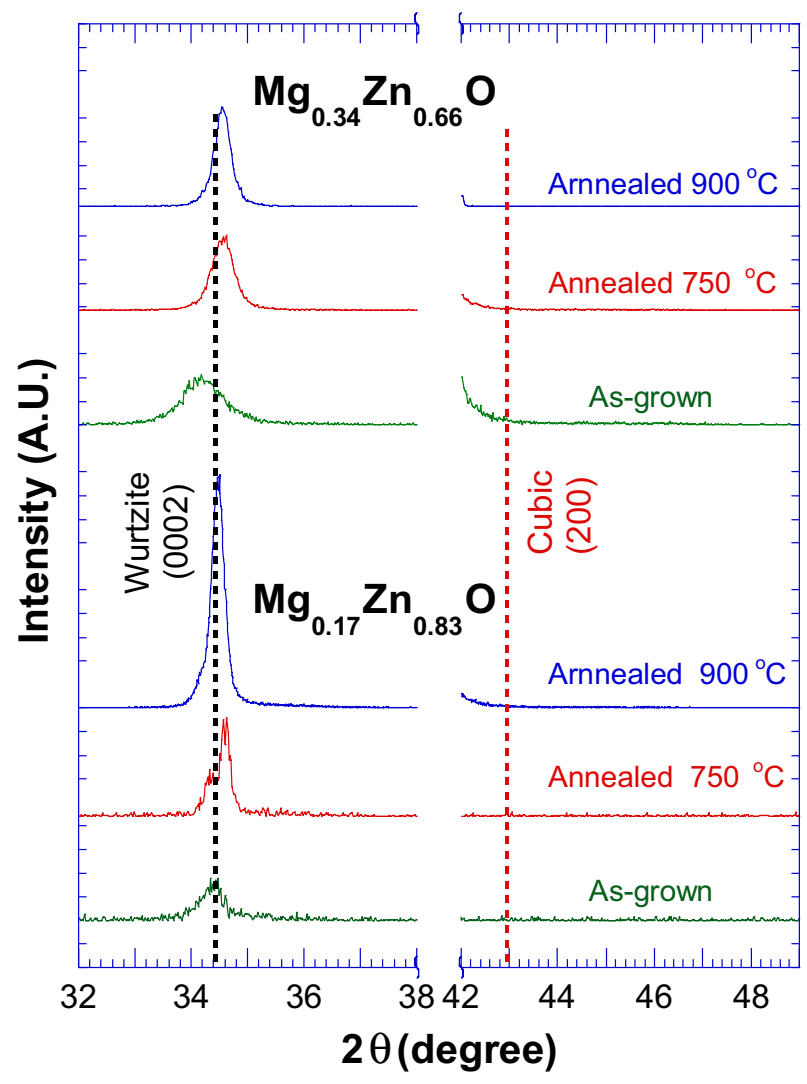

Fig. 1 The XRD spectra of the samples with relatively low Mg composition: $\mathrm{Mg}_{0.17} \mathrm{Zn}_{0.83} \mathrm{O}$ and $\mathrm{Mg}_{0.34} \mathrm{Zn}_{0.66} \mathrm{O}$. The spectra are for the as-grown samples and for samples that were annealed at 750 and $900{ }^{\circ} \mathrm{C}$. The main diffraction peak is due to the wurtzite structure; no diffraction due to cubic structure is detectable
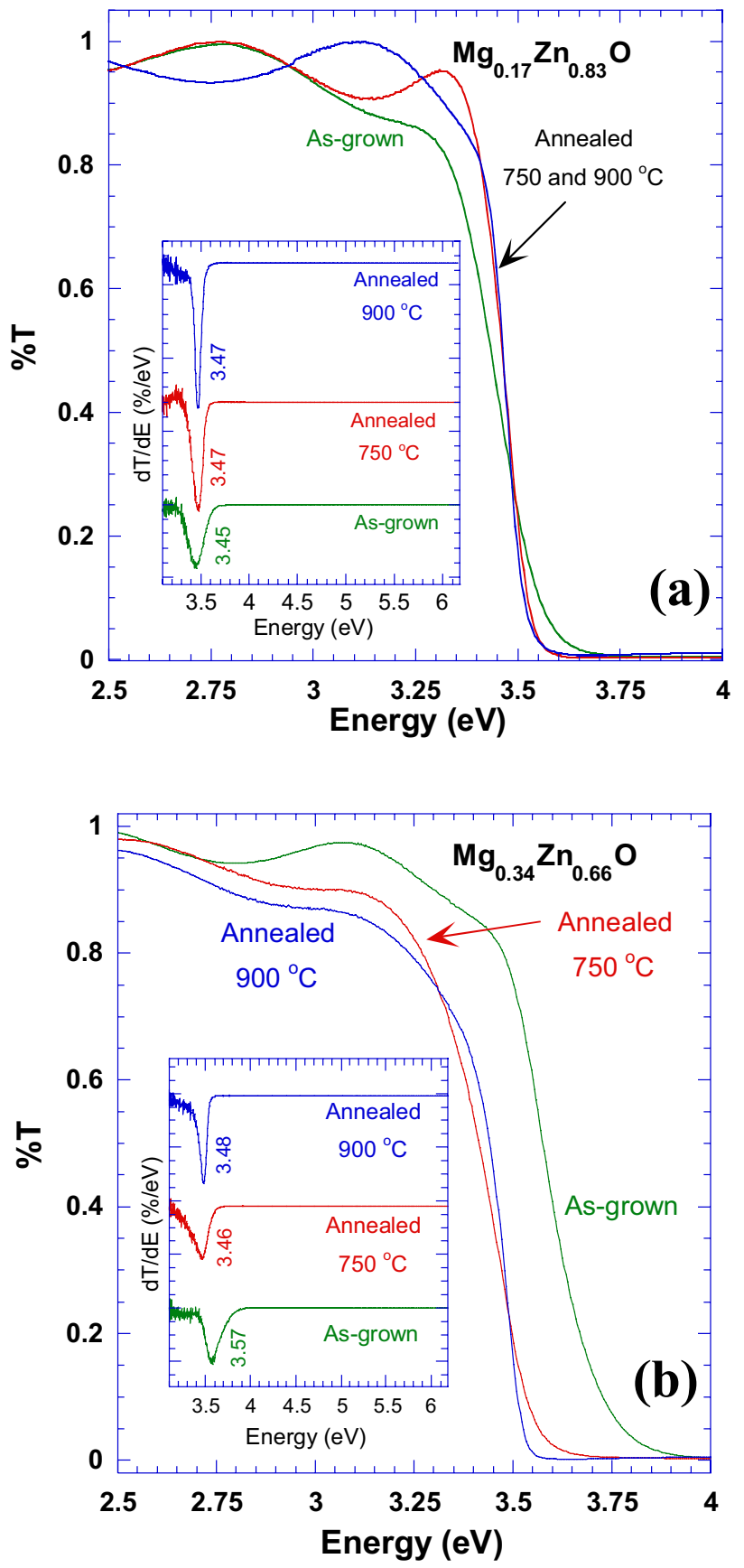

Fig. 2 Transmission spectra of $\mathrm{Mg}_{0.17} \mathrm{Zn}_{0.83} \mathrm{O}$ (a), and $\mathrm{Mg}_{0.34} \mathrm{Zn}_{0.66} \mathrm{O}$ (b), for the as-grown and annealed samples. The inset is the derivative method dT/dE for determining the bandgaps of the alloys. No meaningful shift in the gap energy, nor deep-UV bandgaps, due to phase separation are present

spectrum of the alloy is not decreasing in a sharp manner at the spectral-range of the bandgap, but rather exhibits an Urbach-type band-edge tailing. This band-edge for the alloys can be explained in terms of in-gap density of states due to structural and morphology defects as well as alloy inhomogeneities $[20,21]$. We previously found that the derivative 
Fig. 3 In a are XRD spectra of the high Mg composition samples for as-grown and annealed samples, showing the extent of the phase separation. As-grown $\mathrm{Mg}_{0.52} \mathrm{Zn}_{0.48} \mathrm{O}$ and $\mathrm{Mg}_{0.72} \mathrm{Zn}_{0.28} \mathrm{O}$, both have the wurtzite structure. After annealing at $900{ }^{\circ} \mathrm{C} \mathrm{Mg}_{0.52} \mathrm{Zn}_{0.48} \mathrm{O}$ exhibits an additional small diffraction corresponding to the cubic structure (see short range focused spectrum in purple), while in $\mathrm{Mg}_{0.72} \mathrm{Zn}_{0.28} \mathrm{O}$ the cubic diffraction already appears at $750{ }^{\circ} \mathrm{C}$. Asgrown $\mathrm{Mg}_{0.80} \mathrm{Zn}_{0.20} \mathrm{O}$ has the cubic structure: the $750{ }^{\circ} \mathrm{C}$ annealing caused it to be phase separated into the cubic and wurtzite structures. The peak of the sapphire substrate was subtracted from the spectra. An SEM image showing the characteristic morphology of our alloys is presented in (b). (Color figure online)

method yields a good measure of the alloy's bandgap; sometime referred to as the optical gap rather than the fundamental gap [19]. The energies of the optical gaps are usually somewhat lower than those of the fundamental gaps. The XRD spectra indicate that both as-grown samples have a single-phase wurtzite structure; no cubic diffraction is detectible. Moreover, upon annealing at up to $900{ }^{\circ} \mathrm{C}$ both samples retain their original single-phase wurtzite structure. The transmission spectra in Fig. 2 concur with the XRD analysis. Specifically, no significant shift in the bandgap energy is evident as a result of the annealing process. If the alloy were phase-separated, the bandgap would have a noticeable shift to lower energy relative to that of the as-grown, corresponding to a bandgap of precipitates with a $\mathrm{Zn}$-rich component. Moreover, the transmission spectra in principle should also have an absorption signature at the high-energy regime, corresponding to the bandgap of a $\mathrm{Mg}$-rich phase precipitates. Examination of the transmission spectrum and its derivative at high energies did not reveal any such features. In light of these findings it can be concluded that for $\mathrm{Mg}$ composition up to $\sim 34 \%$, and for a temperature of $900{ }^{\circ} \mathrm{C}$, these alloys are thermally stable.

In the following section results regarding alloys at the high $\mathrm{Mg}$-composition regime are discussed. Figure $3 \mathrm{a}$ presents the XRD of $\mathrm{Mg}_{0.52} \mathrm{Zn}_{0.48} \mathrm{O}, \mathrm{Mg}_{0.72} \mathrm{Zn}_{0.28} \mathrm{O}$, and $\mathrm{Mg}_{0.80} \mathrm{Zn}_{0.20} \mathrm{O}$, and Fig. $3 \mathrm{~b}$ is the scanning electron microscopy (SEM) image showing the characteristic granular morphology of our samples. As can be seen in Fig. 3a, the as-grown $\mathrm{Mg}_{0.52} \mathrm{Zn}_{0.48} \mathrm{O}$, and $\mathrm{Mg}_{0.72} \mathrm{Zn}_{0.28} \mathrm{O}$, both have the wurtzite structure. Upon annealing at $900{ }^{\circ} \mathrm{C}$ the $\mathrm{Mg}_{0.52} \mathrm{Zn}_{0.48} \mathrm{O}$ alloy is found to exhibit an additional small diffraction peak corresponding to the cubic structure, while the $\mathrm{Mg}_{0.72} \mathrm{Zn}_{0.28} \mathrm{O}$ is found to be phase separated already at $750{ }^{\circ} \mathrm{C}$. In contrast, the $\mathrm{Mg}_{0.80} \mathrm{Zn}_{0.20} \mathrm{O}$ has sufficient $\mathrm{Mg}$ concentration that enabled it to be crystalized with the cubic structure; however, $750{ }^{\circ} \mathrm{C}$ annealing caused it to be phase separated into the cubic and wurtzite structures. In a similar manner to the low Mg-composition samples, transmission studies were conducted. Figure 4 shows the transmission spectra characteristics of one of the high $\mathrm{Mg}$ composition samples, as an example where features due to phase separation after annealing are present. Figure 5 shows the
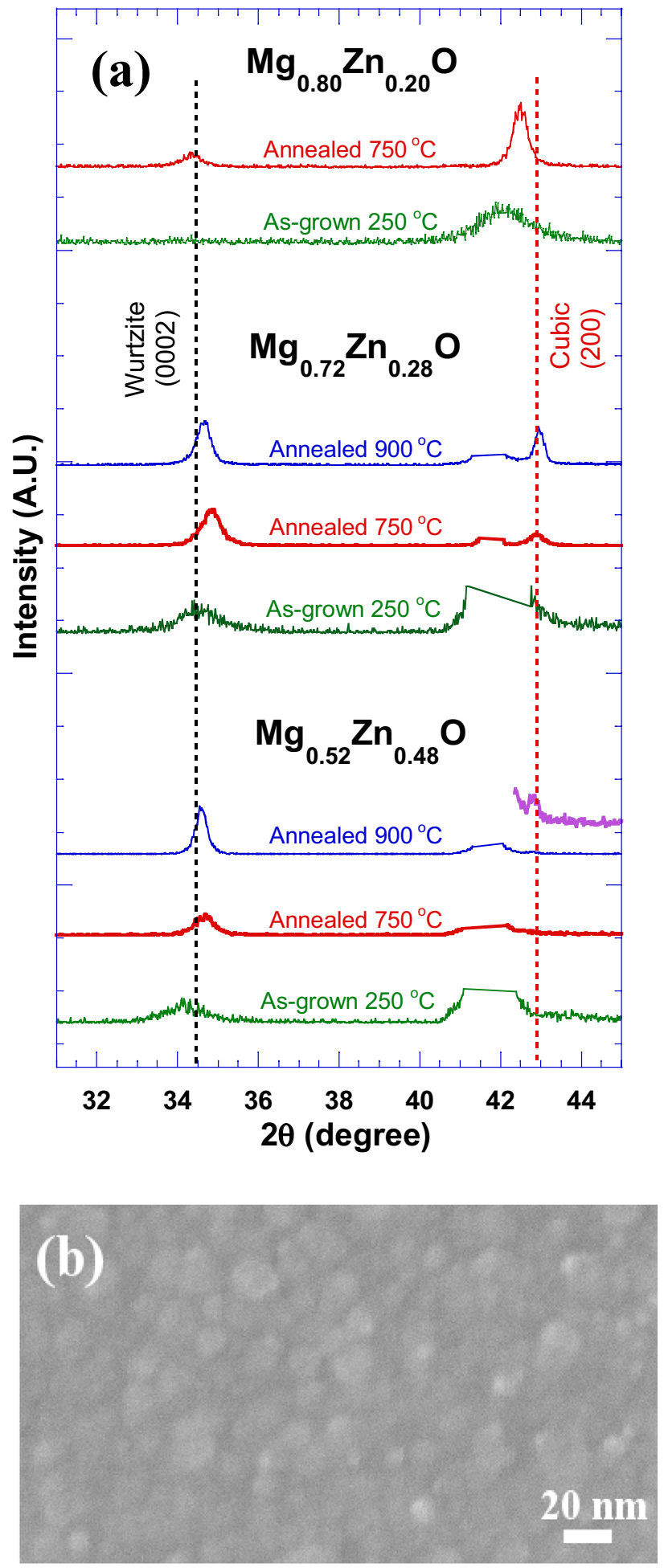

transmission analysis from which the bandgaps of the high Mg-composition alloys were determined. As can be seen in Fig. 5, after annealing the bandgaps of $\mathrm{Mg}_{0.52} \mathrm{Zn}_{0.48} \mathrm{O}$ and $\mathrm{Mg}_{0.72} \mathrm{Zn}_{0.28} \mathrm{O}$ shifted to lower energies corresponding to $\mathrm{Zn}$-rich phases, and moreover bandgaps in the deep-UV $\sim 6 \mathrm{eV}$ due to $\mathrm{Mg}$-rich phase are detectable. The transmission 


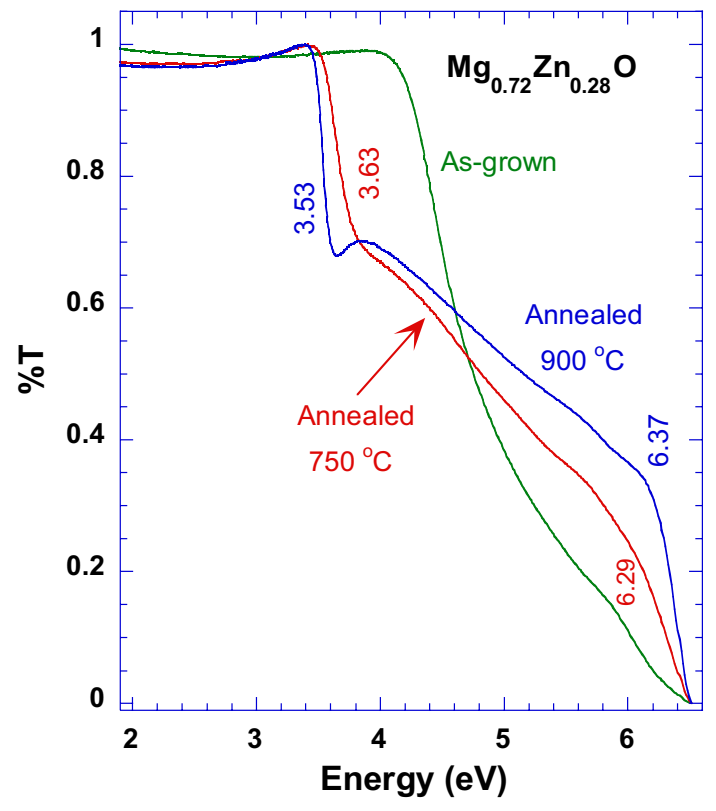

Fig. 4 The transmission spectra of $\mathrm{Mg}_{0.72} \mathrm{Zn}_{0.28} \mathrm{O}$ for the as-grown and annealed samples. After annealing the spectra exhibit distinct absorption features due to phase separation

results correlate well with those of the XRD, and as such the deep-UV bandgaps can be assigned to originate from the cubic structures.

In order to further discuss the thermal stability of the $\mathrm{Mg}_{\mathrm{x}} \mathrm{Zn}_{1-\mathrm{x}} \mathrm{O}$, the properties of the alloys are summarized in Figs. 6 and 7. Figure 6 shows the compositional dependence of the optical gap for the as-grown alloys as well as the optical gap structural transition of the annealed alloys, and in Fig. 7 the temperature behavior as a function of composition is depicted. Specifically, the open data points in Fig. 7, starting at $1100{ }^{\circ} \mathrm{C}$ and above, are adapted from phase-diagram studies of $\mathrm{Mg}_{\mathrm{x}} \mathrm{Zn}_{1-\mathrm{x}} \mathrm{O}$ ceramics that were grown under thermodynamics equilibrium conditions [10, 11, 22-24], while the data points below that temperature are from the present study. As can be seen in Fig. 7, the asgrown films (temperature $250{ }^{\circ} \mathrm{C}$ ) of composition $\mathrm{x}=0.17$ to 0.72 were determined to be a single-phase wurtzite structure, while the $\mathrm{x}=0.8$ alloy was found to crystalize with the cubic structure. Thus the growth method used for this research resulted in a single-phase wurtzite alloys for $\mathrm{Mg}$ compositions up to $\sim 72 \%$. This composition is significantly larger than those predicted for $\mathrm{Mg}_{\mathrm{x}} \mathrm{Zn}_{1-\mathrm{x}} \mathrm{O}$ ceramics that were grown under thermodynamics equilibrium conditions, to be discussed later.

In the following discussion we focus on the alloys with the wurtzite structure. As was mentioned above, after annealing at 750 and $900{ }^{\circ} \mathrm{C}$, the alloys with composition up to $x=0.34$ retain their original wurtzite structure, while the alloys with the high $\mathrm{Mg}$ content, $\mathrm{x}=0.52$ and 0.72 , undergo

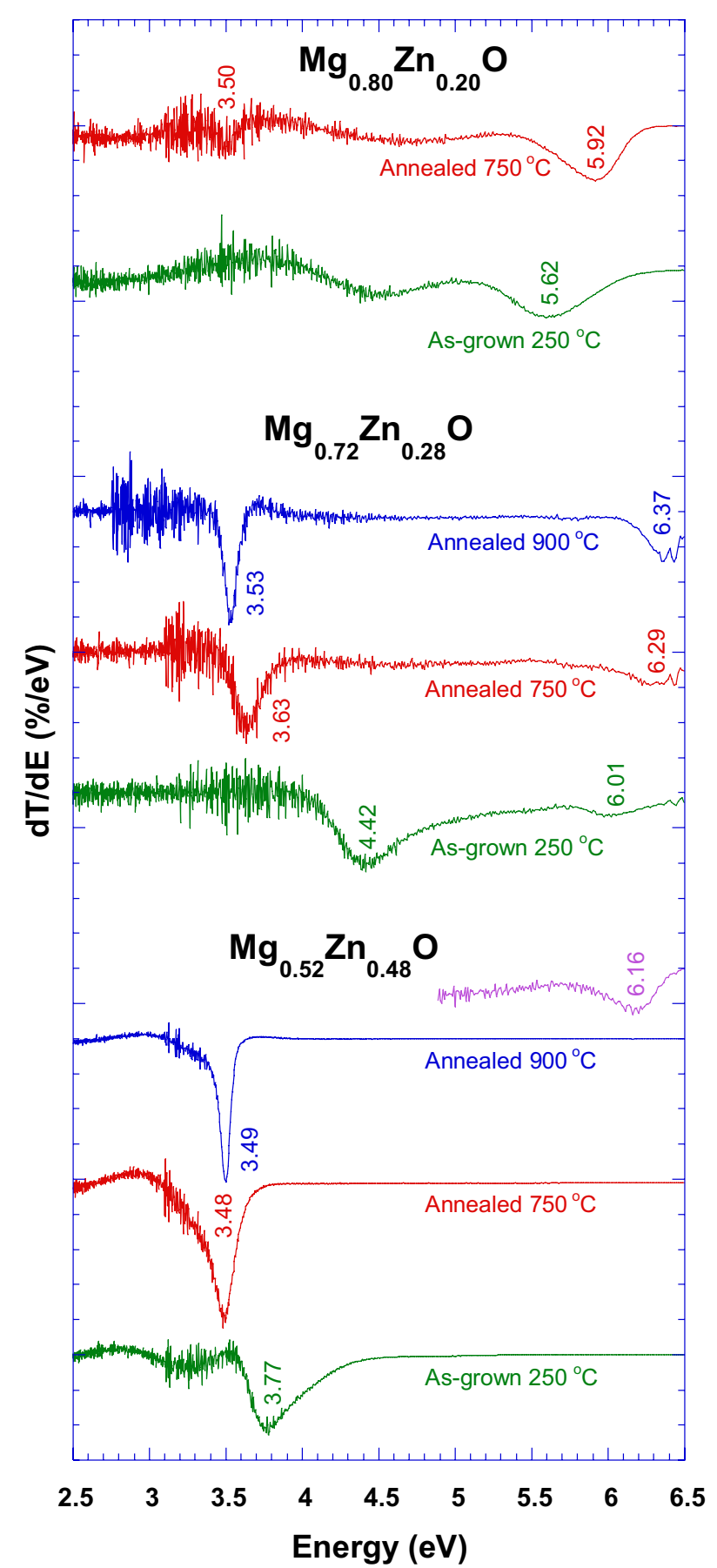

Fig. 5 The derivative (dT/dE) spectra and the inferred bandgaps of the high $\mathrm{Mg}$ composition samples. Upon annealing, the bandgaps of $\mathrm{Mg}_{0.52} \mathrm{Zn}_{0.48} \mathrm{O}$ and $\mathrm{Mg}_{0.72} \mathrm{Zn}_{0.28} \mathrm{O}$ shifted significantly to lower energies, relative to those of the as-grown wurtzite samples, indicative of precipitation of $\mathrm{Zn}$-rich domains. Also bandgaps in the deep-UV $\sim 6 \mathrm{eV}$ due to the $\mathrm{Mg}$-rich phase are detectable. For $\mathrm{Mg}_{0.52} \mathrm{Zn}_{0.48} \mathrm{O}$ the cubic phase is detectable in the focused spectrum $\sim 6.16 \mathrm{eV}$. The as-grown $\mathrm{Mg}_{0.72} \mathrm{Zn}_{0.28} \mathrm{O}$ exhibit a weak signal at $\sim 6.01 \mathrm{eV}$ that can assigned to negligible $\mathrm{Mg}$-rich precipitates. The as-grown $\mathrm{Mg}_{0.80} \mathrm{Zn}_{0.20} \mathrm{O}$ is metastable cubic, marking the $\mathrm{x} \sim 0.72$ as the upper limit for achieving wurtzite alloy. Some of the features in the spectra are fringe patterns 


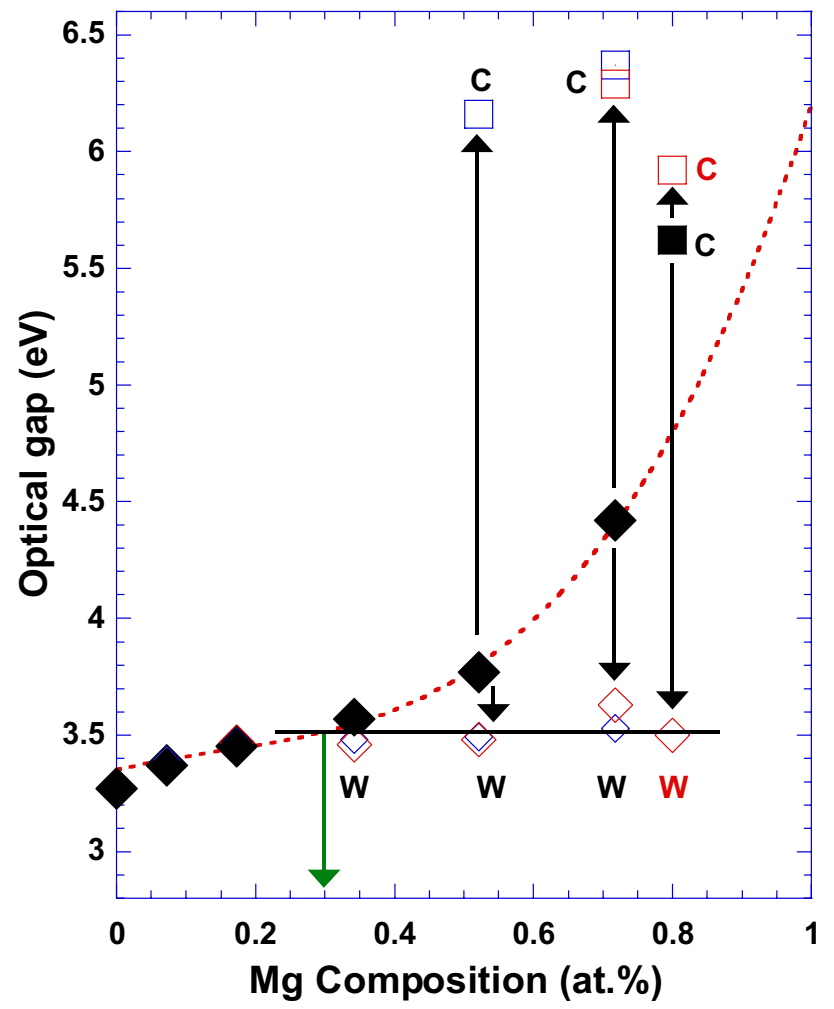

Fig. 6 Compositional dependence of the optical gap for the asgrown and annealed alloys. The data points for the as-grown wurtzite alloys are designated as filled diamond symbols, while that of the cubic alloy is the filled square. The dashed line indicates the bowing behavior of the optical gap of as-grown wurtzite alloys. The arrows indicate the transitions of the bandgaps after annealing; the open square symbols are the bandgaps for the cubic phases, and the open diamonds are for the wurtzite structure (red for annealed at $750{ }^{\circ} \mathrm{C}$ and blue for $900{ }^{\circ} \mathrm{C}$ ). The solid horizontal line indicates the wurtzite bandgap value after annealing. These gaps all converged to $\sim 3.5 \mathrm{eV}$ corresponding to $\mathrm{Mg}$ composition in the range of $\sim 30 \%$. (Color figure online)

structural changes in which wurtzite as well as cubic phases co-exist. Notably, the $x=0.34$ alloy does not have a detectible XRD after annealing, corresponding to the cubic phase; however, due to the small bandgap shift (see Fig. 6) we surmise that this composition is the onset for a phase separation. With regard to the high $\mathrm{Mg}$ composition, the alloy with $\mathrm{x}=0.52$ shows structural stability at $750{ }^{\circ} \mathrm{C}$ with a single phase wurtzite, and is phase separated at $900{ }^{\circ} \mathrm{C}$, while the alloy with $\mathrm{x}=0.72$ is phase separated already at $750^{\circ} \mathrm{C}$. Abinitio density functional theory (DFT) studies regarding the structural properties of $\mathrm{Mg}_{\mathrm{x}} \mathrm{Zn}_{1-\mathrm{x}} \mathrm{O}$ have determined that a phase transition from the wurtzite to the cubic phase should occur for a critical Mg concentration 50\% [25]. This result explains the occurrence of the observed phase separation for the alloy with $\mathrm{x}=0.52$ (and that with $\mathrm{x}=0.72$ ); upon providing the thermodynamics condition, the alloy precipitates into its more preferable stable equilibrium state.

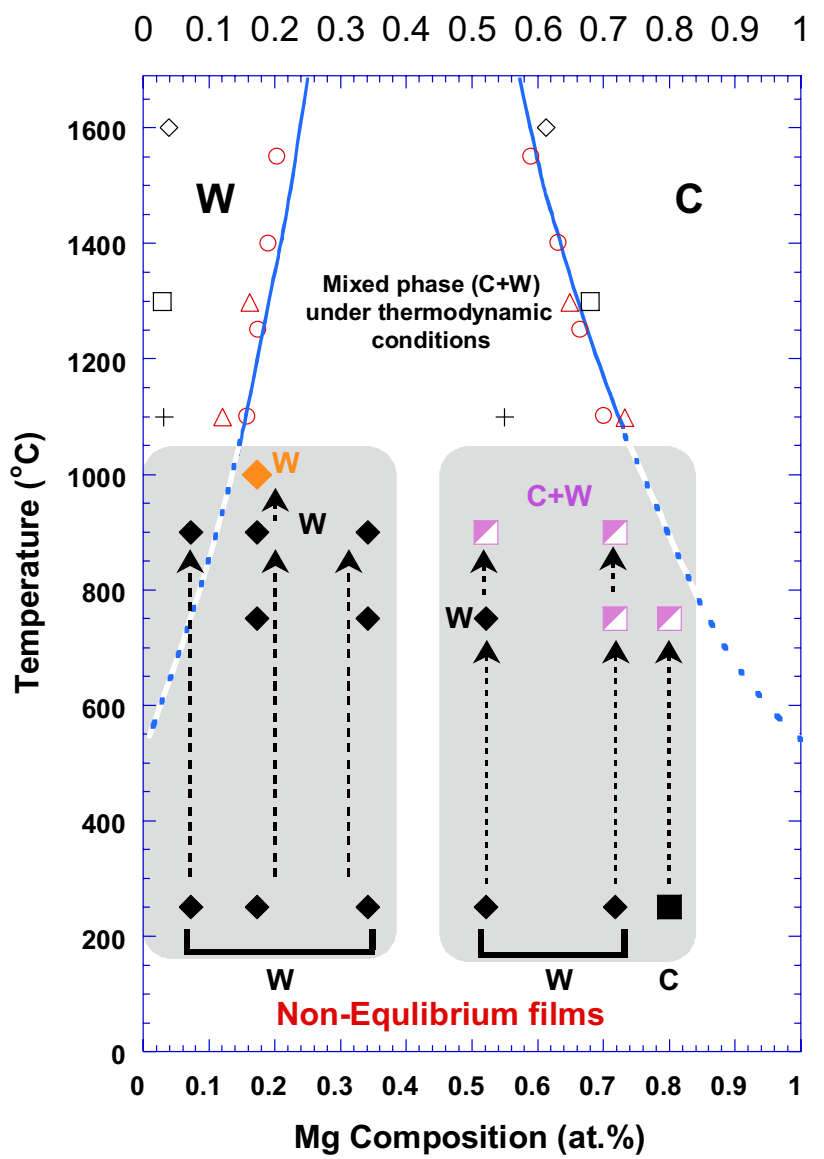

Fig. 7 A diagram for the phases of $\mathrm{Mg}_{\mathrm{x}} \mathrm{Zn}_{1-\mathrm{x}} \mathrm{O}$ alloy system. The data above $1000{ }^{\circ} \mathrm{C}$ are for ceramics grown under thermodynamics equilibrium conditions (open symbols) [10, 11, 22-24]; the curved lines (solid and dashed) are a guide for some of these data points. The solid and semisolid symbols are data points for our $\mathrm{Mg}_{\mathrm{x}} \mathrm{Zn}_{1-\mathrm{x}} \mathrm{O}$ films that were grown far from thermodynamics equilibrium. The data points at $250{ }^{\circ} \mathrm{C}$ correspond to the as-grown films: the dashed arrows represent the impact of annealing on their structure, diamond symbols are for the wurtzite (W) phase, and square semi-filled symbols are for the mixed cubic and wurtzite $(\mathrm{W}+\mathrm{C})$ phase

An interesting issue that is evident from Fig. 7 is that the experimental phase diagram for the ceramics has somewhat conflicting results pertaining to the solubility limit of $\mathrm{MgO}$ in the $\mathrm{ZnO}$ wurtzite matrix. Some experimental data show a very limited solubility $\mathrm{x} \sim 0.05[10,23,24]$, while others found it to be much a more substantial $\mathrm{x} \sim 0.15$ (at $\left.1100{ }^{\circ} \mathrm{C}\right)[11,22]$. In order to gain insight into this topic we chose the $\mathrm{Mg}_{0.17} \mathrm{Zn}_{0.83} \mathrm{O}$ that was found to exhibit no evidence for phase separation, and drove it to a further equilibrium state that approached that of the ceramics via high-temperature annealing at $1000^{\circ} \mathrm{C}$. As can be seen in Fig. 7, this temperature is in close proximity to the growth temperature $\sim 1100{ }^{\circ} \mathrm{C}$ of the ceramics at the low Mg-composition regime. Figures 8 and 9 present the XRD and the bandgap characteristics, respectively, which indicate that 


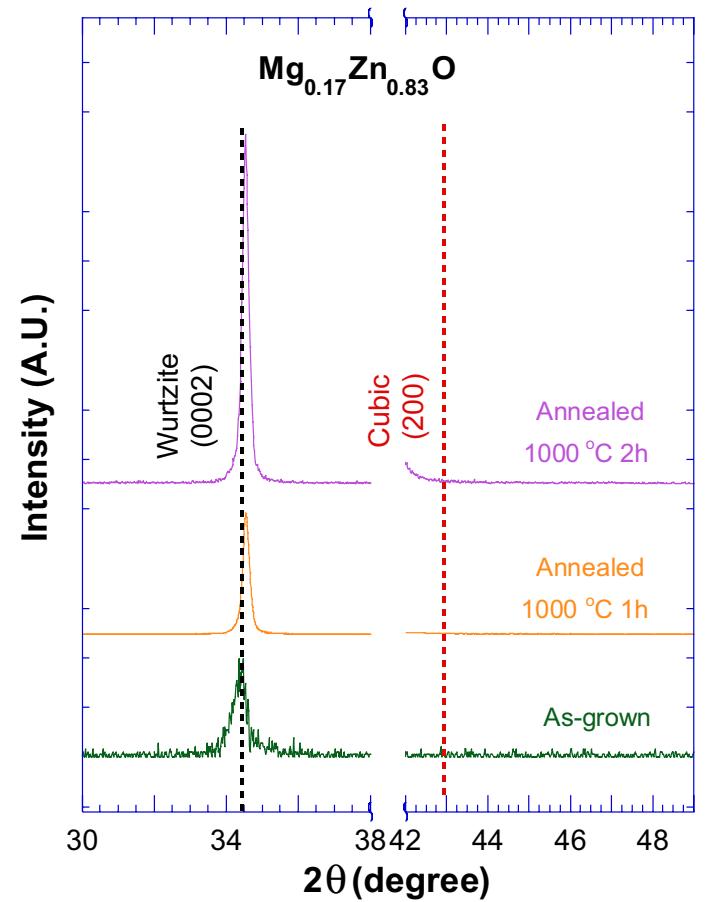

Fig. 8 XRD spectra of the as-grown $\mathrm{Mg}_{0.17} \mathrm{Zn}_{0.83} \mathrm{O}$ wurtzite alloy, and of the samples annealed at high-temperature $1000{ }^{\circ} \mathrm{C}$, for $1 \mathrm{~h}$ (orange) and $2 \mathrm{~h}$ (red). The alloy did not show diffraction peaks corresponding to the presence of the cubic structure. (Color figure online)

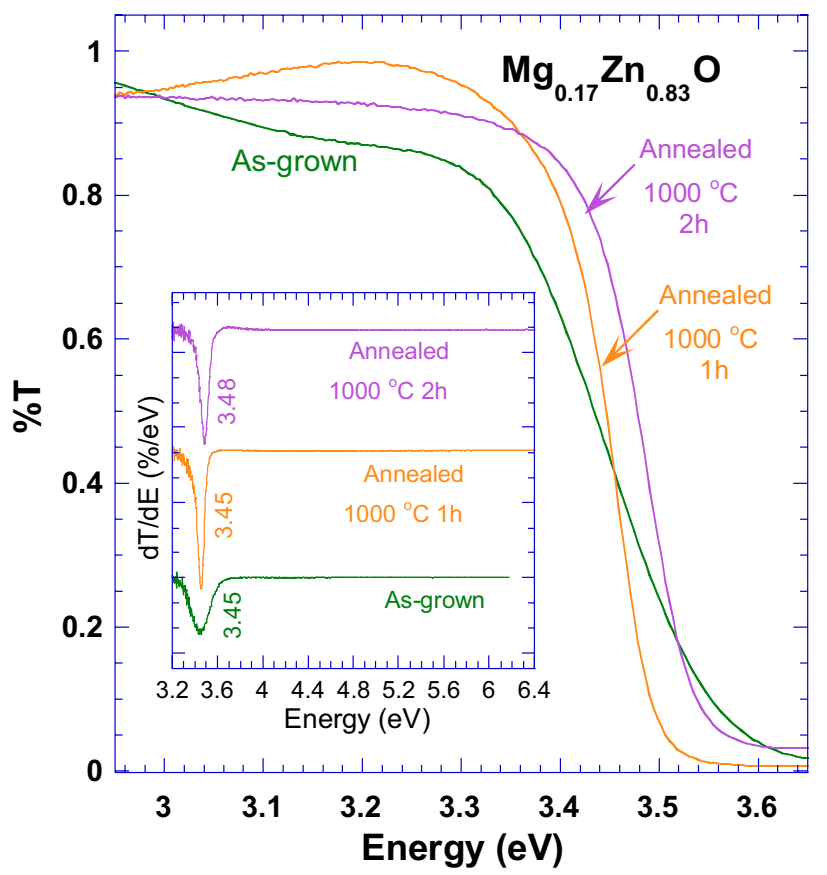

Fig. 9 Transmission spectra of the $\mathrm{Mg}_{0.17} \mathrm{Zn}_{0.83} \mathrm{O}$ alloy at the high temperature annealing of $1000{ }^{\circ} \mathrm{C}$. No features due to phase changes after annealing are evident. The data point for this study is included in the diagram of Fig. 7 (orange diamond symbol). (Color figure online) no structural changes took place after the high-temperature annealing process, implying the stability of this sample. The data point for this alloy is included in the diagram of Fig. 7 (orange diamond) and is in the range of the solubility limit for the $\sim 15 \%$ ceramics, which is of similar composition to our alloy. Our results agree with the prediction of the higher limit for $\mathrm{Mg}$ incorporation given by the groups in references $[11,22]$, suggesting that wurtzite $\mathrm{Mg}_{\mathrm{x}} \mathrm{Zn}_{1-\mathrm{x}} \mathrm{O}$ with relatively high $\mathrm{Mg}$-composition are achievable, not only as metastable alloys but even as thermodynamics equilibrium alloys.

Lastly the stability limit of our alloys is discussed, and supporting evidence from Raman scattering analysis and a model calculation will be presented. Annealing studies have been previously reported with a variety of research focuses [6-8, 26-30]; in the following we will summarize some of those which are closely related to our work. As is depicted in Fig. 6, the value of the bandgaps of the high-Mg composition alloys $(\mathrm{x}=0.52,0.72$, and 0.8$)$ after annealing all converge to the value of $\sim 3.5 \mathrm{eV}$ (see Fig. 6). This bandgap corresponds approximately to an alloy with $\mathrm{Mg}$ composition in the range of $\mathrm{x} \sim 0.25 \pm 0.05$, implying that the solubility limit at $900{ }^{\circ} \mathrm{C}$ of our samples is for $\mathrm{Mg}$ composition in that range. Studies on the phase stability of cubic $\mathrm{Mg}_{0.55} \mathrm{Zn}_{0.45} \mathrm{O}$ grown by metal-organic chemical vapor deposition found that the phase separation occurred after annealing at $850{ }^{\circ} \mathrm{C}$ [6]. The stability limit of sol-gel $\mathrm{Mg}_{\mathrm{x}} \mathrm{Zn}_{1-\mathrm{x}} \mathrm{O}$ was determined to be $\sim x=0.23$ [7]. Additionally, a phase stability study of wurtzite $\mathrm{Mg}_{0.22} \mathrm{Zn}_{0.78} \mathrm{O}$ film grown via PLD found that with post-growth annealing at $1000{ }^{\circ} \mathrm{C}$, the bandgap of this alloy reduced to $3.56 \mathrm{eV}$, corresponding to an alloy with $\mathrm{x}=0.15$ [8]. This study thus concluded that the thermodynamic stability limit of $\mathrm{MgO}$ in $\mathrm{Mg}_{\mathrm{x}} \mathrm{Zn}_{1-\mathrm{x}} \mathrm{O}$ is about $\mathrm{x}=0.15$ [8]. Our predicted value for the stability limit that was inferred from several samples is at a higher range of $\mathrm{x} \sim 0.25 \pm 0.05$, as is indicated in Fig. 6. As can be seen in Fig. 6, the bandgap of the lower $\mathrm{Mg}$ alloys is not a strong function of the composition, which imposes some uncertainty in the experimental approach for pinpointing a single value for the solubility limit.

Additionally, previous work on the thermal stability of RF sputtered $\mathrm{Mg}_{0.4} \mathrm{Zn}_{0.6} \mathrm{O}$ thin film and superlattices has been conducted at annealing temperatures of 600 and $800{ }^{\circ} \mathrm{C}$ as a function of time [27]. Their annealing studies of $\mathrm{Mg}_{0.4} \mathrm{Zn}_{0.6} \mathrm{O}$ film have shown that the hexagonal crystallinity of the film was improved. Moreover, upon annealing at $800{ }^{\circ} \mathrm{C}$ for $5 \mathrm{~min}, \mathrm{MgZnO}$ cubic precipitation was observed, while annealing at $600{ }^{\circ} \mathrm{C}$ has required a longer time of at least $3 \mathrm{~h}$ to initiate the cubic precipitation [27]. In our case, the $\mathrm{Mg}_{0.52} \mathrm{Zn}_{0.48} \mathrm{O}$ that was annealed at $900{ }^{\circ} \mathrm{C}$ was found to be phase separated, a result which agrees with their study. A different study of rapid and high-efficiency laser alloying of $\mathrm{MgZnO}$ nanocrystals examined the relationship between annealing temperature and the limit value of homogeneous 
$\mathrm{Mg}$ in the nanocrystals [28]. Their study concluded that annealing at temperatures of $400{ }^{\circ} \mathrm{C}, 600{ }^{\circ} \mathrm{C}$, and $800{ }^{\circ} \mathrm{C}$, a $\mathrm{MgO}$ cubic phase appeared for nanocrystals with $\mathrm{Mg}$ composition of 62 at.\%, 53 at.\%, and 39 at.\%, respectively. Specifically, for annealing at $800{ }^{\circ} \mathrm{C}$ the limit value of $\mathrm{Mg}$ in their nanoalloys was indicated to be $\sim 22$ at.\% [28]. Our result of the solubility limit in the sputtered thin films, which is $25 \% \pm 5 \%$, is similar to theirs.

To further investigate the solubility limit of the alloys, Raman spectroscopy was employed. Our UV-lasers, at $325 \mathrm{~nm}(3.8 \mathrm{eV})$ and $244 \mathrm{~nm}(5.1 \mathrm{eV})$, due to their resonance with the bandgaps of the alloys, enables strong Raman scattering from the LO mode of the wurtzite structure [31]. Figure 10 shows the Raman spectra of the as-grown and annealed $\mathrm{Mg}_{\mathrm{x}} \mathrm{Zn}_{1-\mathrm{x}} \mathrm{O}$ alloys. In Fig. 11 the LO Raman

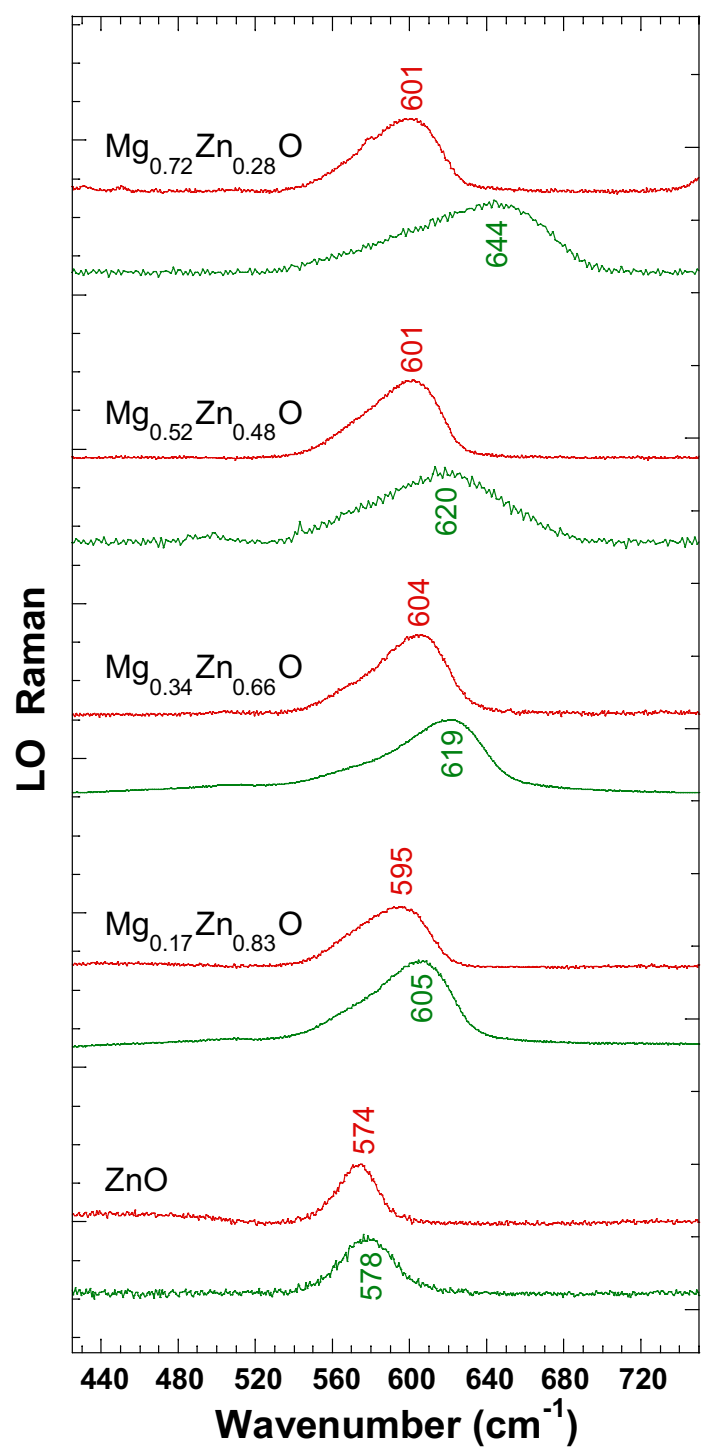

Fig. 10 The Raman spectra of the as-grown (green) and $900{ }^{\circ} \mathrm{C}$ annealed (red) $\mathrm{Mg}_{\mathrm{x}} \mathrm{Zn}_{1-\mathrm{x}} \mathrm{O}$. (Color figure online)

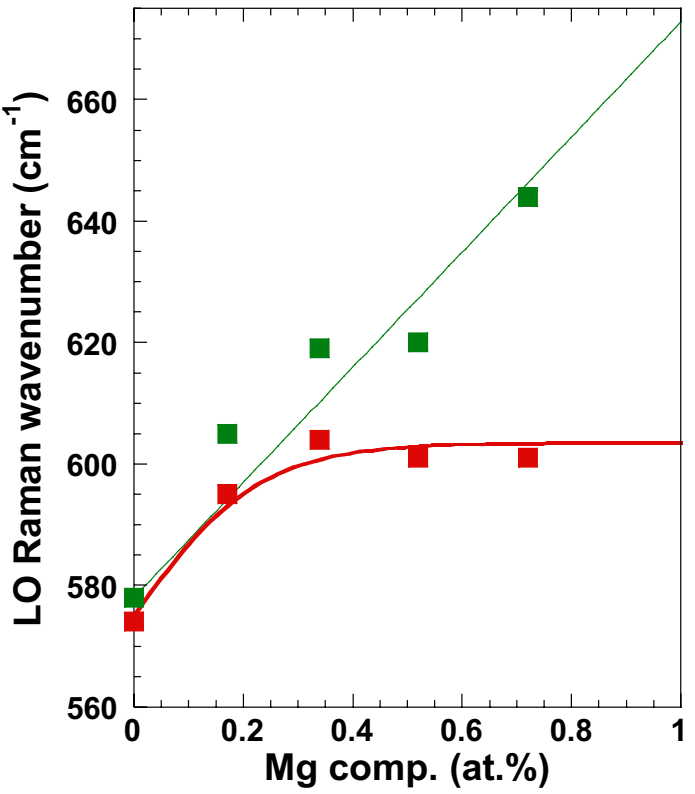

Fig. 11 The LO-Raman mode as a function of alloy composition for as-grown (green) and $900{ }^{\circ} \mathrm{C}$ annealed (red) samples. The Raman mode of the annealed alloys exhibits a saturation behavior. The red line is a fit to our data using the model in Eq. 1. (Color figure online)

frequency as a function of composition is plotted for the as-grown alloys and for the alloys after annealing at $900{ }^{\circ} \mathrm{C}$. As can be seen in Fig. 11, the LO mode frequency of the asgrown samples exhibits a linear increase with Mg composition, while that of the annealed alloys was found to exhibit a saturation-type behavior. This mode behavior can be modeled with a saturation function of the form [32,33]:

$\omega(x)=\omega_{0}+b \tanh \left(\frac{x}{x_{0}}\right)$

where $\omega_{0}$ and $b$ are constants, and $x_{0}$ is the Mg composition for which the LO mode becomes saturated. A fit to the data resulted in $\omega_{0}=575 \mathrm{~cm}^{-1}, \mathrm{~b}=28.47$, and $x_{0}=0.23$ (23\%). The Raman analysis thus indicates that the solubility limit is for $\mathrm{Mg}$ composition $\mathrm{x} \sim 0.23$. This result, up to the experimental error, concurs with the solubility limit of $\mathrm{x} \sim 0.25 \pm 0.05$ obtained via the optical gap analysis, shown in Fig. 6.

A key point of the above studies is that $\mathrm{Mg}$ has considerable solubility in the wurtzite matrix, which makes $\mathrm{Mg}_{\mathrm{x}} \mathrm{Zn}_{1-\mathrm{x}} \mathrm{O}$ a viable alloy system for UV-applications. 


\section{Conclusions}

Single-phase wurtzite $\mathrm{Mg}_{\mathrm{x}} \mathrm{Zn}_{1-\mathrm{x}} \mathrm{O}$ thin films at composition $0 \leq \mathrm{x} \leq 0.72$ were grown via a sputtering technique as metastable alloys. The optical bandgaps of these alloys span the UV-range of $\sim 3.3-4.42 \mathrm{eV}$. The thermal stability studies indicated that at up to $900{ }^{\circ} \mathrm{C}$, alloys with relatively low $\mathrm{Mg}$ composition up to approximately $\mathrm{x}=0.34$ are highly stable and retain their structural and optical bandgap properties. In contrast, the alloys above this composition were found to be thermally unstable and exhibited structural separation for which wurtzite and cubic phases coexists in the alloy's matrix. The optical gaps of this group of alloys is at $\sim 3.5 \mathrm{eV}$ for the wurtzite phase and $\sim 6 \mathrm{eV}$ for the cubic phase. The bandgap analysis indicated that the solubility limit of the $\mathrm{Mg}_{\mathrm{x}} \mathrm{Zn}_{1-\mathrm{x}} \mathrm{O}$ thin films is at composition $\mathrm{x} \sim 0.25 \pm 0.05$. A similar value for the solubility limit was also ascertained from Raman scattering studies: the LO-mode followed a saturation-type behavior with a solubility limit at composition $\mathrm{x} \sim 0.23$. The results are discussed in the context of available phase-diagrams for stable-state ceramics alloys, that unlike our thin films were grown under thermodynamics equilibrium conditions.

Acknowledgements This research was supported by the U.S. Department of Energy, Office of Basic Energy Sciences, Division of Materials Science and Engineering under award DE-FG02-07ER46386.

Open Access This article is distributed under the terms of the Creative Commons Attribution 4.0 International License (http://creativeco mmons.org/licenses/by/4.0/), which permits unrestricted use, distribution, and reproduction in any medium, provided you give appropriate credit to the original author(s) and the source, provide a link to the Creative Commons license, and indicate if changes were made.

\section{References}

1. A. Ohtomo, M. Kawasaki, T. Koida, K. Masubuchi, H. Koinuma, Y. Sakurai, Y. Yoshida, T. Yasuda, Y. Segawa, Appl. Phys. Lett. 72, 2466 (1998)

2. H. Peng, P.F. Ndione, D.S. Ginley, A. Zakutayev, S. Lany, Phys. Rev. X 5, 021016 (2015)

3. F. Yun, M.A. Reshchikov, L. He, T. King, H. Morkoç, S.W. Novak, L. Wei, J. Appl. Phys. 92, 4837 (2002)

4. J.E. Greene, J. Vac. Sci. Technol. B Microelectron. Process. Phenom. 1, 229 (1983)

5. T.F. Kuech, S.E. Babcock, L. Mawst, Appl. Phys. Rev. 3, 040801 (2016)
6. Z.G. Ju, C.X. Shan, C.L. Yang, J.Y. Zhang, B. Yao, D.X. Zhao, D.Z. Shen, X.W. Fan, Appl. Phys. Lett. 94, 101902 (2009)

7. M. Wang, E.J. Kim, S. Kim, J.S. Chung, I.-K. Yoo, E.W. Shin, S.H. Hahn, C. Park, Thin Solid Films 516, 1124 (2008)

8. A. Ohtomo, R. Shiroki, I. Ohkubo, H. Koinuma, M. Kawasaki, Appl. Phys. Lett. 75, 4088 (1999)

9. D.M. Roessler, W.C. Walker, Phys. Rev. Lett. 17, 319 (1966)

10. E.R. Segnit, A.E. Holland, J. Am. Ceram. Soc. 48, 409 (1965)

11. R. Hansson, P.C. Hayes, E. Jak, Scand. J. Metall. 33, 355 (2004)

12. T. Takagi, H. Tanaka, S. Fujita, S. Fujita, Jpn. J. Appl. Phys. 42, L401 (2003)

13. F. Alema, O. Ledyaev, R. Miller, V. Beletsky, A. Osinsky, W.V. Schoenfeld, J. Cryst. Growth 435, 6 (2016)

14. J.-S. Liu, C.-X. Shan, B.-H. Li, Z.-Z. Zhang, K.-W. Liu, D.-Z. Shen, Opt. Lett. 38, 2113 (2013)

15. V. Awasthi, S.K. Pandey, V. Garg, B.S. Sengar, P. Sharma, S. Kumar, C. Mukherjee, S. Mukherjee, J. Appl. Phys. 119, 233101 (2016)

16. Y.N. Hou, Z.X. Mei, Z.L. Liu, T.C. Zhang, X.L. Du, Appl. Phys. Lett. 98, 103506 (2011)

17. C.-J. Ku, Z. Duan, P.I. Reyes, Y. Lu, Y. Xu, C.-L. Hsueh, E. Garfunkel, Appl. Phys. Lett. 98, 123511 (2011)

18. J.C. Manifacier, J. Gasiot, J.P. Fillard, J. Phys. E 9, 1002 (1976)

19. D. Thapa, J. Huso, H. Che, M. Huso, J.L. Morrison, D. Gutierrez, M.Grant Norton, L. Bergman, Appl. Phys. Lett. 102, 191902 (2013)

20. D. Thapa, J. Huso, K. Miklos, P.M. Wojcik, D.N. McIlroy, J.L. Morrison, C. Corolewski, M.D. McCluskey, T.J. Williams, M.Grant Norton, L. Bergman, J. Mater. Sci. Mater. Electron. 28, $2511(2017)$

21. J. Huso, H. Che, D. Thapa, A. Canul, M.D. McCluskey, L. Bergman, J. Appl. Phys. 117, 125702 (2015)

22. Y.D. Kondrashev, Y.A. Omel'chenko, Russ. J. Inorg. Chem. 9, 937 (1964)

23. L.L.Y. Chang, R.C. Kaldon, J. Am. Ceram. Soc. 59, 275 (1976)

24. J.F. Sarver, F.L. Katnack, F.A. Hummel, J. Electrochem. Soc. 106, 960 (1959)

25. I. Gorczyca, H. Teisseyre, T. Suski, N.E. Christensen, A. Svane, J. Appl. Phys. 120, 215704 (2016)

26. R. Ghosh, D. Basak, J. Mater. Sci. Mater. Electron. 18, 141 (2007)

27. J.Z. Chen, C.-H. Li, I.-C. Cheng, Thin Solid Films 520, 1918 (2012)

28. P. Liu, H. Wang, J. Chen, X. Li, H. Zeng, Sci. Rep. 6, 28131 (2016)

29. W. Liu, S. Gu, S. Zhu, J. Ye, F. Qin, S. Liu, X. Zhou, L. Hu, R. Zhang, Y. Shi, Y. Zheng, J. Cryst. Growth 277, 416 (2005)

30. D.Y. Jiang, D.Z. Shen, K.W. Liu, C.X. Shan, Y.M. Zhao, T. Yang, B. Yao, Y.M. Lu, J.Y. Zhang, Semicond. Sci. Technol. 23, 035002 (2008)

31. J. Huso, J.L. Morrison, J. Mitchell, E. Casey, H. Hoeck, C. Walker, L. Bergman, W.M. Hlaing, Oo, M.D. McCluskey, Appl. Phys. Lett. 94, 061919 (2009)

32. B.E. Chalker, Mar. Biol. 63, 135 (1981)

33. B. Zamanlooy, M. Mirhassani, IEEE Trans. Very Large Scale Integr. VLSI Syst. 22, 39 (2014) 